\title{
Predictors of infant and young feeding practices among children 6-23 months old in Bennatsemayworeda, Ethiopia
}

\begin{abstract}
Feeding practices of children under two years directly affect their nutritional status, impacting survival. Many observational studies showed that maternal knowledge of optimal child feeding practices is basic to keep health of a child. However, maternal knowledge, attitude and practices towards child feeding and associated factors of pastoralist children were not well documented in BennaTsemayWoreda, South Omo Zone, and Southern Ethiopia. Therefore this study was designed to assess child feeding practices and associated factors among pastoralist children aged 6-23months in Benna Tsemay Woreda, South Omo Zone, and Southern Ethiopia. A community-based cross sectional study was conducted among 645 pastoralist children aged 6-23 months from February-March 2016. A stratified random sampling technique was used to select kebeles (smallest administrative unit) and children. Out of $32 \mathrm{kebeles}$, six were randomly selected. Data was collected using a structured questionnaire, 24hour food recall and focus group discussions. Quantitative and qualitative data were collected. Quantitative data was analysed using SPSS for windows version 20.0. Qualitative data was analyzed based on thematic content analysis. Bivariate and multivariable logistic regression analyses were conducted. Crude odds ratio (COR) and adjusted odds ratio (AOR) with 95\% confidence interval were reported. About $45.7 \%$ of the mothers didn't have adequate knowledge about IYCF practices with $54.3 \%$ showing poor child feeding. It was found that, $65.6 \%$ of the study participated children consumed $<4$ food groups in the last 24-hrs preceding the survey with mean dietary diversity score (DDS) being $3.7 \pm 1.48$. However, only $11.5 \%$ of the children consumed $<3$ meals/day with mean meal frequency of $1.88 \pm 0.31$. This study showed, having large number of under five children (2-4 child) (AOR=0.46, 95\% CI, 0.25-0.86), polygamous marriage ( $\mathrm{AOR}=0.42,95 \% \mathrm{CI}, 0.24-0.72)$, fathers having primary education $(\mathrm{AOR}=5.24,95 \% \mathrm{CI}, 1.27-21.52)$, being from pastoralist $(\mathrm{AOR}=10.52,95 \% \mathrm{CI}, 4.85-22.82)$, richest wealth quantile household $(\mathrm{AOR}=23.01,95 \% \mathrm{CI}, 8.92-59.31)$, use of treated water $(\mathrm{AOR}=$ $3.06,95 \% \mathrm{CI}, 1.70-5.50)$, time to fetch water $(\mathrm{AOR}=6.24,95 \% \mathrm{CI}, 3.73-$ $10.44)$, birth interval between the recent two birth $(\mathrm{AOR}=2.18,95 \% \mathrm{CI}$, $1.30-3.66)$ and farming as maternal occupation (AOR $=0.08,95 \% \mathrm{CI}, 0.03$ -
\end{abstract}

\section{Introduction}

Infant and young child feeding practices directly affect the nutritional status of children under two years, impacting on child survival. ${ }^{1}$ Appropriate child feeding practices and behaviors of parents have positive effect on growth of infants and young children. ${ }^{2}$ Many studies shown that maternal knowledge of optimal child feeding practices like exclusive breastfeeding for six months, continued breastfeeding and the timely transition to adequate complementary food is basic to keep health of a child. ${ }^{3}$ Inadequate maternal knowledge about feeding practices is often a greater determinant of malnutrition than lack of food. ${ }^{4}$ According to Ethiopian Health and Nutrition Research Institute (2014), reported: Over $44 \%$ of the pastoral communities are severely food insecure. The pastoralists depend mainly on two food groups: cereal $(97 \%) \&$ dairy products $(>50 \%)$. IYCF practice is very poor among Ethiopian pastoral communities. Breast feeding up to 2 years is in the range of $35.3-71.1 \%$. Consumption of animal products is high in pastoral areas where cows or goat milk is a major component of the diet for pastoralist children in addition to breast feeding. Milk is therefore, found to be a fundamental constituent of complementary
Volume 8 Issue 6 - 2018

\author{
Anteneh Tadesse \\ Southern Agricultural Research Institute, Jinka Agricultural \\ Research Center, Ethiopia
}

Correspondence: Anteneh Tadesse, Southern Agricultural Research Institute, Jinka Agricultural Research Center, Jinka, p.o.box 96, Ethiopia, Email antutspt@yahoo.com

Received: October 21, 2018 | Published: November 20, 2018

$0.20)$ were significantly associated with maternal knowledge on child feeding $(\mathrm{p}<0.05)$. Being older age mothers $(\geq 30$ years $)(\mathrm{AOR}=0.14,95 \% \mathrm{CI}, 0.03$ $0.63)$, use of treated water $(\mathrm{AOR}=12.47,95 \% \mathrm{CI}, 5.82-26.7)$, time to fetch water $(\mathrm{AOR}=1.78,95 \% \mathrm{CI}, 1.00-3.16)$, major source of information on child feeding $(\mathrm{AOR}=0.01,95 \% \mathrm{CI}, 0.001-0.23)$, farming as maternal occupation $(\mathrm{AOR}=0.16,95 \% \mathrm{CI}, 0.06-0.45)$, inavailability of health service $(\mathrm{AOR}=5.81$, $95 \% \mathrm{CI}, 2.04-16.5$ ) and minimum dietary diversity ( $\mathrm{AOR}=2.37,95 \% \mathrm{CI}, 1.20$ 4.67) were significantly associated with maternal practice on child feeding of pastoralist children in BennaTsemayWoreda $(\mathrm{p}<0.05)$. In conclusion, large numbers of mothers have inadequate knowledge and poor practices about IYCF practices with low DDS. Being from pastoralist, large number of under five, elder mothers, polygamous marriage, and poor health service are factors for mother's inadequate and poor practices towards child feeding. Therefore, the authors recommend interventions targeting on community-based nutrition education on IYCF, dietary diversity, cultural food taboos, and family planning in BennaTsemay pastoralist community.

Keywords: child feeding practices, associated factors, pastoralist area, Ethiopia

diets in every pastoralist household. Most children in pastoralist areas are mainly feed on cereal-based, less nutritious diets with no fruits or vegetables. ${ }^{5}$ An improvement of diet diversity is crucial for both quality and quantity of their intakes. Attention should therefore be given to decisions taken by the mother during complementary feeding. Despite the wide role of breastfeeding and complementary feeding for infants and young children, the indigenous knowledge, attitude and practices towards child feeding and associated factors among pastoralist children in the study area are not well documented. That's why this research is motivated to assess indigenous mother's knowledge, attitude and practice on child feeding and associated factors among pastoralist children age 6-23months.

\section{Materials and methods}

\section{Description of the study area}

The study was conducted in BennaTsemayWoreda, South Omo Zone of Southern Ethiopia. This area is located $739 \mathrm{~km}$ South of Addis Ababa, the capital of Ethiopia and $551 \mathrm{~km}$ South of Hawassa, the capital of SNNPR. There are 32 Kebles in the woreda. According 
to Central Statistical Agency Population projection of 2015, the total population of BennaTseamyworeda is 62,414 out of which 31,638 are males and 30,776 are females. The woreda is named after the two dominant local ethnic groups namely, Benna and Tsemay, which constitute $48.6 \%$ and $36.1 \%$ of the population, respectively. ${ }^{6}$ The remaining $15.3 \%$ of the population is composed of people of other ethnic groups. There are 3 health centers, 27 health posts and 10 medium private clinics provide basic health care for the community at BennaTsemayWoreda. Most of the kebeles are served by health posts, which focus on preventive aspects and are equipped with junior health extension workers. The large portion of the woreda is characterized by arid and semi-arid areas or pastoralists and agro-pastoralists communities. The livelihood of the local people in the district is based on mixed farming but pastoralism predominates over crop production.

\section{Study design and period}

Community-based cross sectional study was used to assess mother's knowledge, attitude and practices towards child feeding and associated factors among pastoralist children aged 6-23months in the study area. The study employed both qualitative and quantitative methods to collect data from February-March 2016.

\section{Study population}

Randomly selected mothers-children pair's 6-23months old living in the selected households in BennaTsemayWoreda.

\section{Sample Size determination}

Sample size estimation was carried out for associated factors using double population proportion formula. Accordingly, the following assumptions were used: $50 \%$ expected variability, $95 \%$ confidence interval (CI), $5 \%$ margin of error, 1.5 design effect and $10 \%$ nonresponse rate. Finally, an Epi-Info software version 7.0.8.3. Statistical application with the above assumptions provided a sample size of 646 households and this was the total sample size of the study.

\section{Sampling technique}

A stratified random sampling technique was used to select kebeles ad pastoralist children. There are 32kebeles in BennaTsemayworeda. The kebeles was stratified based on the pattern of livelihood system of the communities into pastoralist, agro pastoralist and farmers. Simple random sampling was used to select two kebeles from each startum and a total of six kebeles were selected out of $32 \mathrm{kebeles}$ A sampling frame was prepared by listing all households that have 6-23months old children in the selected kebeles. Once's households with under 6-23month children were identified, the total calculated sample size was distributed for each kebeles by using proportional to size allocation. After that, simple random sampling was used to select the required number of children from the respective kebeles. Finally, the youngest child from the household in the restricted age group was taken as an index child regardless of sex discrimination. Only one child was selected using lottery method when more than one child is found in a given household.

\section{Inclusion and Exclusion criteria}

Inclusion criteria: All mothers-children pairs aged 6-23months whose parents have lived at least for six months in BennaTsemayworeda were included.

Exclusion criteria: Children and mothers/caregivers who were not found at home during three visits were excluded from the study.

\section{Study variables}

\section{Dependent variable}

Mother's knowledge, attitude and practices (KAP)

\section{Independent variables}

i. Socio-demographic and socio-economic variables: sex of the child, age of child, religion, ethnicity, mother's marital status, maternal educational status, maternal occupation, maternal age, household family sizes, number of under-five children, wealth index etc

ii. Maternal and child related factors: birth order of the child, birth interval, and source of information for IYCF, history of illness in the past two weeks and immunization status

iii. Health service availability and health seeking behaviour factors: availability of health extension service, history of illness in the past two weeks and immunization status.

iv. Water supply, sanitation and hygiene factors: source of drinking water, type of toilet/latrine facilities, method of waste disposal, method of water treatment, etc

\section{Data collection tools}

\section{Structured questionnaire}

A pretested and structured questionnaire was used to assess socio-demographic and economic characteristics, maternal and child's characteristics, water supply, sanitation and personal hygiene conditions, health service availability and health seeking behaviour and mother's knowledge and practice towards child feeding. Mother's knowledge and practice towards child feeding in children 6-23months of age was assessed using structured questionnaire according to the current recommendation of World Health Organization. ${ }^{7}$ Early initiation of breast feeding, exclusive breastfeeding, time of introduction of solid, semi-solid or soft foods, minimum dietary diversity and minimum meal frequency for non-breastfed children was determined.

\section{A 24hours dietary diversity}

Food groups consumed by pastoralist children were collected with 24hour recall method with the assistance of their respective mother. Dietary diversity score (DDS) was used to assess the dietary diversity of children. The dietary diversity score (DDS) was calculated by giving a score of " 1 " for those who consumed the food item and a score of " 0 " for those who did not consume the food item over the past 24hours. According to WHO 2010 guideline a total of seven food groups was considered in this study i.e. (1) grains, roots and tubers, (2) pulses, legumes and nuts, (3) dairy products (milk, yogurt, cheese), (4) flesh foods (meat, poultry, fish and liver/organ meats), (5) eggs, (6) vitamin A-rich fruits and vegetables, (7) other fruits and vegetables.

\section{Focus group discussion}

Three Focus Group Discussion (FDG) ( $\mathrm{n}=6$ for each) was investigated to obtain in-depth information of mother's attitude and perceptions towards child feeding and its challenges. The FGD was conducted by categorizing the mothers into three groups, mothers from pastoralist in one group, mothers from agro-pastoralist in one group and mothers from farmers in analysis. Normality of continuous variables was checked using histograms and Q-Q plots. Descriptive statistics such as frequency, percentages and mean and another group. 
The number of participant was 6 for each group which have a direct involvement in child care. The discussions were carried out by the local language which was translated by translator and with one note taker. The FDG was facilitated by the moderator. Theme for discussion was also presented by the moderator. Tape recorder was used to record voices of participants. The transcripts were thematically analyzed after translation into English.

\section{Data quality control}

The questionnaire was originally prepared in English and translated to local language "Bennga" and "Tsemayga" and back translated to English by two people for consistency and to avoid information bias. To avoid information bias data collectors were also selected from both Benna and Tsemayethinic groups. Five percent $(5 \%)$ of the questionnaire was pretested in local language to make sure that the questions would clear and could be understood by respondents before formal data collection. The pretest was done out of the study kebeles. A face-to-face interview was used to collect data using structured questionnaire. Data collection on child feeding practices and knowledge of the mother was interviewed in a silent place. For 24hour recall week day was used to record the food item. Standard questionnaire from EDHS and WHO 2010 guidelines was used to collect data. All the potential factors for wealth index were considered. Diploma nurses who are fluent in the local language "Bennga" and "Tsemayga" was used to administer questionnaires. Training was provided for data collectors. Data validity and reliability was maintained through close supervision of data collectors by the principal investigator. The principal investigator supervised and reviews every questionnaire for completeness and logical consistency and corrections was made on the spot.

\section{Data analysis}

First, the data was checked for completeness, coded and entered in to a computer. SPSS for windows version 20.0 (SPSS Inc) was used for statistical data standard deviation was used to present the study results. Bivariate and multivariable logistic regression analyses were conducted to see the association of each independent variable on mother's knowledge, attitude and practices towards child feeding. Both crude odds ratio (COR) and adjusted odds ratio (AOR) with $95 \%$ confidence interval was reported to indicate the strength of association between mother's knowledge, attitude and practices towards child feeding and predictor variables. Significant variables with a p-value less than 0.25 observed in the bivariate analysis were subsequently included in to the multivariable analysis to control potential confounders. In the multivariable logistic regression analysis, variables with a $p$-value of $<0.05$ were considered as statistically significant. Hosmer-Leme show test was performed for model fitness. P-value $>0.05$ was considered a good fit. Linear regression analysis techniques were used for collinearity diagnostics. Multicollinearity effect for potential factors was checked by Variation Inflation Factor (VIF) value greater than 10 and tolerance value less than 0.1 . No collinearity was found. Statistical graphs and tables were used to represent the study results. Household wealth index was estimated from asset and utility services ownership using principal component analysis (PCA) according to the EDHS wealth index (2014). The wealth index was then divided into 5 quintiles. Data from focus group discussions was transcribed, responses arranged in general categories identified in the discussion guide. Common themes were identified, inferences made from each theme and conclusion drawn.

\section{Ethical considerations}

Ethical clearance was obtained from Hawassa University
College of medicine and health science Institutional Review Board (IRB/058/08). Permission was obtained from South Omo Zone and Woreda health offices. Informed consent was obtained from the mother and father of study participating child. Data obtained from each study participant was kept confidential. Nutritional advice was also given for those mothers/caregivers on child feeding.

\section{Results}

\section{Socio-demographic economic characteristics of the study participants}

A total of 645 respondents of children aged 6-23months participated in the study providing an overall response rate of $99.8 \%$. The mean $( \pm \mathrm{SD})$ family sizes of the households were $5.99 \pm 2.43$. The mean $( \pm \mathrm{SD})$ number of under five children per a household was $1.88 \pm 0.65$. Most of head of the households, 442(68.4\%) were farmers by their occupation, whereas $101(15.6 \%)$ were pastoralists, $86(13.3 \%)$ were agro-pastoralists and the rest $14(2.2 \%)$ were employed. Of the total households, $135(20.9 \%)$ were found in the lowest/poorest wealth quintile (Table 1).

Table I Socio-demographic economic characteristics of the study participants $(n=645)$ in BennaTsemayWoreda, South Omo Zone, Southern Ethiopia, 2016

\begin{tabular}{|c|c|c|}
\hline $\begin{array}{l}\text { Socio-demographic } \\
\text { economic variables }\end{array}$ & Frequency $(n)$ & Percentage (\%) \\
\hline \multicolumn{3}{|l|}{ Total family size } \\
\hline 2-3 individuals & 113 & 17.5 \\
\hline 4-5 individuals & 183 & 28.3 \\
\hline$\geq 6$ individuals & 349 & 54 \\
\hline Mean $( \pm S D)$ & $5.99 \pm 2.43$ & \\
\hline \multicolumn{3}{|c|}{$\begin{array}{l}\text { Number of }<5 \text { children in the } \\
\mathrm{HH}\end{array}$} \\
\hline I & 172 & 26.6 \\
\hline 2 & 387 & 59.9 \\
\hline 3 & 77 & 11.9 \\
\hline Mean $( \pm S D)$ & $1.88 \pm 0.65$ & \\
\hline \multicolumn{3}{|l|}{ Father's education } \\
\hline No formal education & 552 & 85.4 \\
\hline Primary education & 48 & 7.4 \\
\hline Secondary education & 37 & 5.7 \\
\hline \multicolumn{3}{|c|}{ Occupation of household head } \\
\hline Farmer & 372 & 57.7 \\
\hline Pastoralist & 161 & 25 \\
\hline Agro-pastoralist & 112 & 17.4 \\
\hline \multicolumn{3}{|l|}{ Wealth index } \\
\hline Lowest & 135 & 20.9 \\
\hline Second & $|2|$ & 18.8 \\
\hline Middle & 134 & 20.8 \\
\hline Fourth & 123 & 19.1 \\
\hline Richest & 132 & 20.5 \\
\hline
\end{tabular}




\section{Maternal and child characteristics}

The mean $( \pm \mathrm{SD})$ age of mothers/cargivers was $26.75 \pm 5.56$, ranged between 18 and 60years. From the study participant, 252(39.0\%) were tradition religion followers, $180(27.9 \%)$ had no religion, the rest 175(27.1) were Protestant in religion. About 602 (93.2\%) of mothers of children were married. About 582(90.1\%) mothers and $552(85.4 \%)$ fathers of the children had no formal education. About $473(73.2 \%)$ of the mothers were in a monogamous and $172(26.6 \%)$ were in polygamy type of marriage. More than half, 361(55.9\%) of the children were male and $284(44.0 \%)$ were female. The mean $( \pm \mathrm{SD})$ age of the children was $12.8 \pm 5.50$ with the minimum and maximum of 6 and 23months, respectively. Most of the child birth order were $1^{\text {st }}$ born $115(17.8 \%), 2^{\text {nd }}$ born $104(16.1 \%), 3^{\text {rd }}$ born $85(13.2 \%)$ and $341(52.8 \%)$ of them were $4^{\text {th }}$ and above born. About $469(72.6 \%)$ of the mothers had a birth interval of less than 23 months, $176(27.2 \%)$ had a birth interval at least 23 months between the recent two births (Table 2).

Table 2 Maternal and child characteristics of the study participants, BennaTsemayWoreda, South Omo Zone, Southern Ethiopia, 2016

\begin{tabular}{|c|c|c|}
\hline $\begin{array}{l}\text { Maternal and child } \\
\text { characteristics }\end{array}$ & Frequency (n) & Percentage (\%) \\
\hline \multicolumn{3}{|l|}{ Maternal age (in years) } \\
\hline $15-19$ years & 22 & 3.4 \\
\hline $20-24$ years & 206 & 31.9 \\
\hline $25-29$ years & 264 & 40.9 \\
\hline$\geq 30$ years & 153 & 23.7 \\
\hline Mean $( \pm S D)$ & $26.75 \pm(5.56)$ & \\
\hline \multicolumn{3}{|l|}{ Religion of mothers } \\
\hline Orthodox & 36 & 5.6 \\
\hline Protestant & 175 & 27.1 \\
\hline Traditional & 252 & 39 \\
\hline No religion & 180 & 27.9 \\
\hline \multicolumn{3}{|l|}{ Marital status of mother } \\
\hline Married & 602 & 93.2 \\
\hline Divorced/separated & 24 & 3.7 \\
\hline Windowed & 19 & 2.9 \\
\hline \multicolumn{3}{|l|}{ Maternal education } \\
\hline No formal education & 582 & 90.1 \\
\hline Primary education & 40 & 6.2 \\
\hline Secondary education & 19 & 2.9 \\
\hline \multicolumn{3}{|l|}{ Maternal occupation } \\
\hline Housewives & 400 & 61.9 \\
\hline Livestock herding & 48 & 7.4 \\
\hline Farming & 185 & 28.6 \\
\hline \multicolumn{3}{|l|}{ Marriage type } \\
\hline Monogamous & 473 & 73.2 \\
\hline Polygamous & 172 & 26.6 \\
\hline Marriage order & & \\
\hline
\end{tabular}

Table Continued

\begin{tabular}{lll}
\hline $\begin{array}{l}\text { Maternal and child } \\
\text { characteristics }\end{array}$ & Frequency $(\mathbf{n})$ & Percentage (\%) \\
\hline Ist wives & 555 & 85.9 \\
2nd wives & 85 & 13.2 \\
\hline
\end{tabular}

Total number of children born to a mother

$\begin{array}{lll}\leq \text { two children } & 217 & 33.6 \\ 3-6 \text { children } & 337 & 52.2 \\ \geq 7 \text { children } & 91 & 14 .\end{array}$

Mean $( \pm$ SD $\quad 3.87 \pm 2.20$

Access to information on child 545

feeding

Yes 100

84.4

No $\quad 15.5$

Sex of children

Male $\quad 361 \quad 55.9$

$\begin{array}{lll}\text { Female } & 284 & 44\end{array}$

Children's age (in month)

6-8 months $\quad 178 \quad 27.6$

9-11 months $\quad 121 \quad 18.7$

12-23 months $346 \quad 53.6$

Mean $( \pm S D) \quad 12.8 \pm(5.50)$

Birth order of the index child

$\begin{array}{lll}\text { Ist born } & 115 & 17.8 \\ \text { 2nd born } & 104 & 16.1 \\ \text { 3rd born } & 85 & 13.2 \\ \geq \text { 4th and above } & 34 \mid & 52.8\end{array}$

Birth interval between the most recent two births

$\begin{array}{lll}\leq 23 \text { months } & 469 & 72.6\end{array}$

$\begin{array}{lll}>23 \text { months } & 176 & 27.2\end{array}$

Water supply, sanitation and personal hygiene conditions

Among the respondents, $240(37.2 \%)$ of the households did not have toilet facility. On the other hand, 96 (14.9\%) of the households dispose their solid wastes in an open field. The main sources of drinking water for the households were from non improved source accounted 617(95.5\%) and improved source accounted 474(73.3\%). About 343 (53.2\%) of the respondents did not treat water before drinking, posing a possible risk of water-borne diseases. This study has revealed that $415(64.2 \%)$ of the mothers practiced washing their hands before and after feeding their child (Table 3 ).

\section{Health service availability and health seeking behavior}

About $461(71.5 \%)$ of the mothers reported that there are health extension services in their kebele. It was also identified that 184 $(28.5 \%)$ of the respondents did not visit a health extension service. About $536(83.0 \%)$ of children were vaccinated except 109 (16.9\%) who had never been vaccinated. About $223(34.5 \%)$ of children had history of illness within the past two weeks prior to the survey (Table 4). 
Table 3 Water supply, environmental and personal hygiene conditions of the study participants $(\mathrm{n}=645)$, BennaTsemayWoreda, South Omo Zone, Southern Ethiopia, 2016

\begin{tabular}{|c|c|c|}
\hline Variable & Frequency (n) & Percentage (\%) \\
\hline \multicolumn{3}{|l|}{ Type of toilet/latrine facilities } \\
\hline $\begin{array}{l}\text { No toilet facility/bush/open } \\
\text { field }\end{array}$ & 240 & 37.2 \\
\hline $\begin{array}{l}\text { Traditional pit latrine without } \\
\text { shade }\end{array}$ & 333 & 51.5 \\
\hline Latrine covered with shade & 69 & 10.7 \\
\hline \multicolumn{3}{|l|}{$\begin{array}{l}\text { Method of solid waste } \\
\text { disposal }\end{array}$} \\
\hline $\begin{array}{l}\text { Dumped in street/open field } \\
\text { disposal }\end{array}$ & 96 & 14.9 \\
\hline Common pit & 66 & 10.2 \\
\hline $\begin{array}{l}\text { Buried/keeping in compound } \\
\text { for fertilizer }\end{array}$ & 132 & 20.2 \\
\hline Burning & 351 & 54.3 \\
\hline \multicolumn{3}{|l|}{ Sources of drinking water } \\
\hline Improved source & 474 & 73.3 \\
\hline Non improved source & 617 & 95.5 \\
\hline \multicolumn{3}{|l|}{ Use of treated water } \\
\hline No & 343 & 53.2 \\
\hline Yes & 302 & 46.8 \\
\hline \multicolumn{3}{|l|}{$\begin{array}{l}\text { Time to fetch water in } \\
\text { minutes }\end{array}$} \\
\hline$<60$ minutes & 365 & 56.5 \\
\hline$\geq 60$ minutes & 280 & 43.3 \\
\hline \multicolumn{3}{|l|}{$\begin{array}{l}\text { Hand washing before and after } \\
\text { feeding child }\end{array}$} \\
\hline Yes & 415 & 64.2 \\
\hline No & 230 & 35.6 \\
\hline
\end{tabular}

Table 4 Health service availability and health seeking behaviour of the study participants $(n=645)$, BennaTsemayworeda, South Omo Zone, Southern Ethiopia, 2016

\begin{tabular}{lll}
\hline Variable & Frequency (n) & Percentage (\%) \\
\hline Availability of health extension & & \\
service in the kebeles & & \\
Yes & 461 & 71.5 \\
No & 184 & 28.5 \\
Child ever vaccinated & & \\
Yes & 536 & 83 \\
No & 109 & 16.9 \\
Type of vaccines taken & & \\
BCG & 427 & 66.1 \\
Polio & 532 & 82.4 \\
Pentavalent & 147 & 22.8 \\
DPT & 407 & 63 \\
\hline
\end{tabular}

Table Continued

\begin{tabular}{lll}
\hline Variable & Frequency (n) & Percentage (\%) \\
\hline Measles & 310 & 48 \\
Vitamin A supplementation & & \\
during the last 6months & & \\
Yes & 218 & 33.7 \\
No & 427 & 66.1 \\
Child's sickness in the past & & \\
2weeks & & \\
Yes & 223 & 34.5 \\
No & 422 & 65.3 \\
Child taken to health & & \\
institution & & \\
during sickness & & 24.6 \\
Yes & 159 & 9.9 \\
No & 64 & \\
\hline
\end{tabular}

\section{Maternal knowledge on child feeding}

Regarding mother's knowledge, 167 (25.9\%) of mothers didn't have information about the importance of breast feeding. About 139 $(21.6 \%)$ of mothers didn't knew the importance of early initiation of breast feeding. About 157 (24.3\%) of mothers didn't knew the importance of colostrums feeding to their baby. Fifty eight $(9.0 \%)$ of mothers didn't have information about exclusive breast feeding. Sixty three $(9.8 \%)$ of mothers think that bottle feeding was harmful (Table 5). A total of five questions, with "Yes" and "No" responses, were included in the questionnaire to assess knowledge of mothers about appropriate child feeding. The mean of correct answers was computed and those who score a value greater than or equal to the mean score were considered adequate knowledge. The mean scored value was 3.28 out of a total of 5 possible correct responses. From the respondents $350(54.3 \%)$ scored greater than or equal to the mean score and considered to have adequate knowledge about appropriate child feeding while 295 (45.7\%) of mothers scored less than the mean score and considered to have inadequate knowledge about appropriate child feeding.

Table 5 Maternal Knowledge towards child feeding, BennaTsemayWoreda, South Omo Zone, Southern Ethiopia, 2016

\begin{tabular}{lcc}
\hline $\begin{array}{l}\text { Maternal knowledge } \\
\text { questions }\end{array}$ & Frequency (n) & Percentage (\%) \\
\hline $\begin{array}{l}\text { Do you know the importance } \\
\text { of } \\
\text { breastfeeding? }\end{array}$ & \\
Yes & 478 & 74.1 \\
No & 167 & 25.9 \\
$\begin{array}{l}\text { Do you know the importance } \\
\text { of early }\end{array}$ & \\
initiation of BF? & & \\
Yes & 506 & 78.4 \\
No & 139 & 21.6 \\
Do you know the importance of colostrum's feeding to your baby? \\
Yes & 488 & 75.7 \\
No & 157 & 24.3 \\
\hline
\end{tabular}


Table Continued

\begin{tabular}{|c|c|c|}
\hline $\begin{array}{l}\text { Maternal knowledge } \\
\text { questions }\end{array}$ & Frequency (n) & Percentage (\%) \\
\hline \multicolumn{3}{|l|}{ Do you have EBF information? } \\
\hline Yes & 587 & 91 \\
\hline No & 58 & 9 \\
\hline \multicolumn{3}{|c|}{$\begin{array}{l}\text { Do you know bottle feeding is dangerous for the } \\
\text { child? }\end{array}$} \\
\hline Yes & 63 & 9.8 \\
\hline No & 582 & 90.2 \\
\hline \multicolumn{3}{|l|}{$\begin{array}{l}\text { Knowledge score of mothers } \\
\text { about child }\end{array}$} \\
\hline \multicolumn{3}{|l|}{ Feeding } \\
\hline $\begin{array}{l}\text { Inadequate knowledge ( }< \\
3.28 \text { ) }\end{array}$ & 295 & 45.7 \\
\hline Adequate knowledge ( $\geq 3.28$ ) & 350 & 54.3 \\
\hline Mean (SD) & $3.28 \pm 1.04$ & \\
\hline
\end{tabular}

\section{Maternal practice towards child feeding}

Based on the result of this study $139(21.6 \%)$ of mothers had lately initiated breastfeeding. Regarding the practice of exclusive breastfeeding, $133(20.6 \%)$ of mothers didn't exclusively breastfed their children for 6months. About $156(24.2 \%)$ of the mothers breastfed less than 8times per day. About 294 (45.5\%) of mothers provided plain water as pre-lacteal feeds for infants before six months. The results showed that about $126(19.5 \%)$ of mothers didn't initiated complementary feeding at 6month. About 157 (24.3\%) of mothers didn't provided colostrums to their infants. Approximately 152 $(23.6 \%)$ of mothers had used bottle feeding in the last 24hour prior to the data collection (Table 6). In the FGD, mothers were asked about breastfeeding initiation. One of the participants in the FGD responds as follows: "We initiate breast feeding after discharge of placenta. Because it is believed to be bad to breastfeed before the expulsion of placenta. Also the breast should be washed before initiation". Surprisingly most of the participants from the FGDs also agreed with these respondents. This showed that mothers had a positive attitude about breastfeeding initiation among children's aged 6-23months old in the community. Additionally, in the FGDs, mothers were also asked about the provision of colostrums for newborn infants. And it was found that: "We gave colostrums for our newborns, because it helps for discarding waste from our breast and important in secreting the main breast milk for our newborns". This also showed that mothers had a positive attitude about the provision of colostrums for newborn infants in the community.

Similarly, mothers were interviewed about their opinion on exclusive breast feeding in the first six months. And it was indicated from the FGD that: "After obtaining information from $H E W$, we started exclusive breast feeding up to the first 6 months". This indicted that mothers had a positive opinion on exclusive breast feeding in the first six months. From the focus group discussion it was pointed out by majority of the mother's attitude about introduction of complementary feeding showed that: "We start additional food after 6 months. If we give additional food before 6 months, our infants suffer from abdominal cramp. Our infants start additional food after "gore", a cultural practice. "Gore" is a traditional way of assessing if a child is ready to take $C F$, through measuring infant's neck and right arm using a thin local stick". This showed that mothers had a negative attitude about introduction of complementary feeding among children's aged 6-23months old in the community.
Table 6 Child feeding practices of mothers, BennaTsemayWoreda, South Omo Zone, Southern Ethiopia, 2016

\begin{tabular}{|c|c|c|}
\hline $\begin{array}{l}\text { Child feeding practice of } \\
\text { mothers }\end{array}$ & Frequency (n) & Percentage (\%) \\
\hline \multicolumn{3}{|l|}{$\begin{array}{l}\text { Initiated breast feeding } \\
\text { immediately }\end{array}$} \\
\hline \multicolumn{3}{|l|}{ within an hour after birth } \\
\hline Yes & 506 & 78.4 \\
\hline No & 139 & 21.6 \\
\hline \multicolumn{3}{|l|}{$\begin{array}{l}\text { Exclusively breastfed for the } \\
\text { first six }\end{array}$} \\
\hline \multicolumn{3}{|l|}{ months of child's life } \\
\hline Yes & 512 & 79.4 \\
\hline No & 133 & 20.6 \\
\hline \multicolumn{3}{|l|}{$\begin{array}{l}\text { Breast feeding frequency } \geq 8 \\
\text { times }\end{array}$} \\
\hline \multicolumn{3}{|l|}{ per day/ in 24 hour } \\
\hline Yes & 428 & 66.4 \\
\hline No & 156 & 24.2 \\
\hline \multicolumn{3}{|l|}{$\begin{array}{l}\text { Plain water used as pre lacteal } \\
\text { feeding }\end{array}$} \\
\hline \multicolumn{3}{|l|}{ for new born infant } \\
\hline Yes & 294 & 45.6 \\
\hline No & 351 & 54.4 \\
\hline \multicolumn{3}{|l|}{$\begin{array}{l}\text { Started complementary feeding } \\
\text { at }\end{array}$} \\
\hline \multicolumn{3}{|l|}{6 month } \\
\hline Yes & 519 & 80.5 \\
\hline No & 126 & 19.5 \\
\hline \multicolumn{3}{|l|}{$\begin{array}{l}\text { Have you ever practiced breast } \\
\text { feeding? }\end{array}$} \\
\hline Yes & 603 & 93.5 \\
\hline No & 41 & 6.4 \\
\hline \multicolumn{3}{|c|}{ Do you currently breast feeding? } \\
\hline Yes & 581 & 90.1 \\
\hline No & 64 & 9.9 \\
\hline \multicolumn{3}{|c|}{$\begin{array}{l}\text { Do you give colostrum's to your } \\
\text { baby? }\end{array}$} \\
\hline Yes & 488 & 75.7 \\
\hline No & 157 & 24.3 \\
\hline \multicolumn{3}{|l|}{$\begin{array}{l}\text { Do you practice bottle feeding } \\
\text { in the }\end{array}$} \\
\hline \multicolumn{3}{|l|}{ past 24hour } \\
\hline No & 493 & 76.4 \\
\hline Yes & 152 & 23.6 \\
\hline \multicolumn{3}{|l|}{$\begin{array}{l}\text { Grading of child feeding } \\
\text { practices }\end{array}$} \\
\hline Poor $(<7.10)$ & 350 & 54.3 \\
\hline Good $(\geq 7.10)$ & 234 & 36.3 \\
\hline Mean (SD) & $7.10 \pm 1.42$ & \\
\hline
\end{tabular}


A total of nine questions, with "Yes" or "No" response, were included in the questionnaire regarding the practice of the study subjects towards appropriate child feeding. The mean of correct answers was computed and those who scored a value greater than or equal to the mean were considered good practice. The mean scored value was 7.10. Out of the total respondents, 234 (36.3\%) scored at least the mean score and considered good practice about appropriate child feeding while 350 (54.3\%) of mothers scored less than the mean score and thus, considered poor practice regarding appropriate child feeding.

\section{Dietary diversity of study participants}

Grain/roots/tubers were the most common food group consumed by children which accounts about $627(97.1 \%)$. The next most commonly consumed food groups were dairy products $440(68.1 \%)$, followed by vitamin A rich fruits and vegetables 371(57.4\%). Fleshed foods $61(9.4 \%)$ such as meat/poultry/fish were not consumed/the least consumed food group by the children in the past 24hours (Figure 1). Food frequency consumption (FFQ) of children showed that, $424(65.6 \%)$ of children consumed less than 4 food groups in the past 24 hours preceding the survey. On the other hand, 221(34.2\%) of the children consumed at least 4 food groups. The mean $( \pm \mathrm{SD}) \mathrm{FFQ}$ for children based on With respect to the different kind's food groups that are used for complementary feeding in the area. It was also indicated in the FGDs that: "Most of the time we prepare complementary food/ porridge from sorghum, moringa leaves and cows milk. We also prepare atmit/soup from only sorghum then we also feed cows milk". Certain food taboos practiced in the community were pointed out in the FGDs by the following quote: "We did not use maize for CF preparation, because it is considered as indigestible for infants and causes abdominal cramp". WHO's recommendations of food groups was 3.7. The minimum meal frequency (MMF) of children showed that, $571(88.4 \%)$ of children consumed at least 3 meals/day.
On the other hand, 77(11.5\%) of children consumed less than 3meals/ day. The mean $( \pm \mathrm{SD})$ meal frequency based on 24-hour recall was $1.88 \pm 0.31$. "We did not give flesh for children for children under three years, because it causes parasites and worms". We don't give egg for children unless they become thin and loss weight". This indicates certain mothers had negative attitude towards the dietary diversity, less attention and care of their children which results in poor nutritional status among their children's aged 6-23months old in the community.

\section{Maternal knowledge on child feeding among children in pastoralist communities}

This study showed, having large number of under five children (2-4 child) $(\mathrm{AOR}=0.46,95 \% \mathrm{CI}, 0.25-0.86)$, polygamous marriage $(\mathrm{AOR}=$ $0.42,95 \% \mathrm{CI}, 0.24-0.72)$, fathers having primary education $(\mathrm{AOR}=$ $5.24,95 \% \mathrm{CI}, 1.27-21.52$ ), being from pastoralist $(\mathrm{AOR}=10.52,95 \%$ $\mathrm{CI}, 4.85-22.82)$, richest wealth quintile household ( $\mathrm{AOR}=23.01,95 \%$ $\mathrm{CI}, 8.92-59.31)$, use of treated water $(\mathrm{AOR}=3.06,95 \% \mathrm{CI}, 1.70$ 5.50), time to fetch water $(\mathrm{AOR}=6.24,95 \% \mathrm{CI}, 3.73-10.44)$, birth interval between the recent two birth ( $\mathrm{AOR}=2.18,95 \% \mathrm{CI}, 1.30-3.66)$ and farming as maternal occupation $(\mathrm{AOR}=0.08,95 \% \mathrm{CI}, 0.03-0.20)$ did show significant association with maternal knowledge on child feeding $(\mathrm{p}<0.05)$ (Table 7). Households having two and above number of under five children had $54 \%$ less likely to be have inadequate knowledge on child feeding than households having one under five children $(\mathrm{AOR}=0.46,95 \% \mathrm{CI}, 0.25-0.86)$. Polygamous marriage is also significantly associated with inadequate knowledge on child feeding. Children whose mothers had in polygamy type of marriage was $58 \%$ less likely to be inadequate knowledge on child feeding as compared to children whose mothers had in monogamy type of marriage $(\mathrm{AOR}=0.42,95 \% \mathrm{CI}, 0.24-0.72)$. Households whose fathers having primary education 5.24times more likely to have inadequate knowledge on child feeding as compared to those households whose fathers have no formal education $(\mathrm{AOR}=5.24,95 \% \mathrm{CI}, 1.27-21.52)$.

Table 7 Predictors of maternal knowledge on child feeding among children aged 6-23months in pastoralist communities, BennaTsemayWoreda, South Omo Zone, Southern Ethiopia, 2016

\begin{tabular}{|c|c|c|c|c|c|}
\hline Variable & $\begin{array}{l}\text { Inadequate } \\
\text { knowledge } \mathrm{n}(\%)\end{array}$ & $\begin{array}{l}\text { Adequate } \\
\text { knowledge } \mathrm{n}(\%)\end{array}$ & Crude OR $(95 \% \mathrm{Cl})$ & $\begin{array}{l}\text { Adjusted OR } \\
(95 \% \mathrm{Cl})\end{array}$ & P-value \\
\hline \multicolumn{6}{|l|}{$\begin{array}{l}\text { Number of under } 5 \\
\text { children in the } \mathrm{HH}\end{array}$} \\
\hline \multicolumn{6}{|l|}{ I } \\
\hline 2 & $59(34.3)$ & $113(65.7)$ & I & 1 & \\
\hline 3 & $197(50.9)$ & $190(49.1)$ & $0.50(0.34,0.73)$ & $0.46(0.25,0.86)$ & 0.015 \\
\hline \multirow[t]{2}{*}{4} & $33(42.9)$ & $44(57.1)$ & $0.69(0.40,1.20)$ & $0.82(0.34,1.93)$ & 0.652 \\
\hline & $6(66.7)$ & $3(33.3)$ & $0.26(0.06,1.08)$ & $0.03(0.005,0.26)$ & $0.001 * *$ \\
\hline \multicolumn{6}{|l|}{ Marriage type } \\
\hline Monogamous & $186(39.3)$ & $287(60.7)$ & I & 1 & \\
\hline Polygamous & $109(63.4)$ & $63(36.6)$ & $0.37(0.26,0.53)$ & $0.42(0.24,0.72)$ & $0.002 * *$ \\
\hline \multicolumn{6}{|l|}{ Fathers education } \\
\hline No primary education & $278(50.4)$ & $274(49.6)$ & I & 1 & $0.021 * *$ \\
\hline Primary education & $6(12.5)$ & $42(87.5)$ & $7.10(2.97,16.97)$ & $5.24(1.27,21.52)$ & 0.446 \\
\hline Secondary education & $7(18.9)$ & $30(81.1)$ & $4.34(1.87,10.06)$ & $1.73(0.4 I, 7.20)$ & 0.236 \\
\hline Collage and above & $3(42.9)$ & $4(57.1)$ & $1.35(0.30,6.10)$ & $0.18(0.01,3.03)$ & \\
\hline
\end{tabular}




\begin{tabular}{|c|c|c|c|c|c|}
\hline Variable & $\begin{array}{l}\text { Inadequate } \\
\text { knowledge n (\%) }\end{array}$ & $\begin{array}{l}\text { Adequate } \\
\text { knowledge n (\%) }\end{array}$ & Crude OR $(95 \% \mathrm{Cl})$ & $\begin{array}{l}\text { Adjusted OR } \\
(95 \% \mathrm{Cl})\end{array}$ & P-value \\
\hline \multicolumn{6}{|l|}{$\begin{array}{l}\text { Occupation of } \\
\text { household head }\end{array}$} \\
\hline Farmer & $181(48.7)$ & $191(51.3)$ & I & I & 0.001 \\
\hline Pastoralist & $78(48.4)$ & $83(51.6)$ & $1.00(0.69,1.46)$ & $10.52(4.85,22.82)$ & $0.001 * *$ \\
\hline Agro-pastoralist & $36(32.1)$ & $76(67.9)$ & $2.00(1.28,3.12)$ & $23.32(9.59,56.70)$ & \\
\hline \multicolumn{6}{|l|}{ Wealth index } \\
\hline Lowest & $84(62.2)$ & $5 I(37.8)$ & I & I & 0.136 \\
\hline Second & $94(77.7)$ & $27(22.3)$ & $0.47(0.27,0.82)$ & $0.55(0.25,1.20)$ & 0.144 \\
\hline Middle & $72(53.7)$ & $62(46.3)$ & $\mathrm{I} .4 \mathrm{I}(0.87,2.30)$ & I.78(0.82, 3.88) & 0.001 \\
\hline Fourth & $22(17.9)$ & $101(82.1)$ & $7.56(4.24,13.47)$ & $19.95(7.53,52.86)$ & $0.001 * *$ \\
\hline Richest & $23(17.4)$ & $109(82.6)$ & $7.80(4.42,13.78)$ & $23.0 I(8.92,59.3 I)$ & \\
\hline \multicolumn{6}{|c|}{ Use of treated water } \\
\hline No & 195(56.9) & $148(43.1)$ & I & I & \\
\hline Yes & $100(33.1)$ & $202(66.9)$ & $2.66(1.93,3.66)$ & $3.06(1.70,5.50)$ & $0.001 * *$ \\
\hline \multicolumn{6}{|c|}{$\begin{array}{l}\text { Time to fetch water in } \\
\text { minutes }\end{array}$} \\
\hline \multicolumn{6}{|l|}{$<60$ minutes } \\
\hline \multirow[t]{2}{*}{$\geq 60$ minutes } & $22 I(60.5)$ & $144(39.5)$ & I & I & \\
\hline & $74(26.4)$ & 206(73.6) & $4.27(3.04,5.99)$ & $6.24(3.73,10.44)$ & $0.001 * *$ \\
\hline \multicolumn{6}{|c|}{$\begin{array}{l}\text { Birth interval between } \\
\text { the recent two birth }\end{array}$} \\
\hline \multicolumn{6}{|l|}{$\leq 23$ months } \\
\hline \multirow[t]{2}{*}{$>23$ months } & $243(51.8)$ & $226(48.2)$ & I & 1 & \\
\hline & $52(29.5)$ & $124(70.5)$ & $2.56(I .76,3.7 I)$ & $2.18(1.30,3.66)$ & $0.003 * *$ \\
\hline \multicolumn{6}{|c|}{ Maternal occupation } \\
\hline Housewives & $102(25.5)$ & 298(74.5) & I & I & 0.107 \\
\hline Livestock herding & $34(70.8)$ & $14(29.2)$ & $0.14(0.07,0.27)$ & $0.35(0.10,1.25)$ & $0.001 * *$ \\
\hline Farming & I57(84.9) & $28(15.1)$ & $0.06(0.03,0.09)$ & $0.08(0.03,0.20)$ & \\
\hline
\end{tabular}

Children whose household heads are pastoralist in their occupation were 10.52 times more likely to be have inadequate knowledge on child feeding than those children's whose household head were farmers in their occupation (AOR $=10.52,95 \% \mathrm{CI}, 4.85-22.82)$. Children whose households with the richest wealth quintile were 23.01 times more likely to be have inadequate knowledge on child feeding than children whose households had lowest wealth quintile (AOR=23.01, 95\% CI, 8.92-59.31). Use of treated water showed statistically significant association with inadequate knowledge on child feeding. Children whose households use treated water had 3.06 times more likely to have inadequate knowledge on child than those whose households did not treat water $(\mathrm{AOR}=3.06,95 \% \mathrm{CI}, 1.70-5.50)$. Children whose households had spent greater than equal to 60 minutes to fetch water had 6.24 times more likely to have inadequate knowledge on child than those whose households had spent less than equal to 60 minutes to fetch water $(\mathrm{AOR}=6.24,95 \% \mathrm{CI}, 3.73-10.44)$. Maternal occupation was statistically significant association with inadequate knowledge on child. Children whose mothers are farmers in their occupation were $92 \%$ less likely to have inadequate knowledge on child compared to those children's whose mothers were housewife in their occupation (AOR=0.08, 95\% CI, 0.03-0.20) (Table 7). Mother's age (in years), maternal education, access to information on child feeding, child ever vaccinated, child ever taken to health institution, hand washing before and after feeding child, availability of health service and minimum dietary diversity didn't show significant association with mothers knowledge towards child feeding $(\mathrm{p}<0.05)$ and adjusted for those significant variables. 
Factors associated with maternal practices on child feeding among children in pastoralist communities

According to the multivariate analysis, older age mothers $(\geq 30$ years $)(\mathrm{AOR}=0.14,95 \% \mathrm{CI}, 0.03-0.63)$, use of treated water $(\mathrm{AOR}=$ $12.47,95 \% \mathrm{CI}, 5.82-26.7)$, time to fetch water(AOR $=1.78,95 \% \mathrm{CI}$, 1.00-3.16), major source of information on child feeding ( $\mathrm{AOR}=0.01$, $95 \% \mathrm{CI}, 0.001-0.23)$, farming as maternal occupation $(\mathrm{AOR}=0.16$, $95 \% \mathrm{CI}, 0.06-0.45$ ), availability of health service (AOR $=5.81,95 \%$ $\mathrm{CI}, 2.04-16.5)$ and minimum dietary diversity $(\mathrm{AOR}=2.37,95 \% \mathrm{CI}$, 1.20-4.67) did show significant association with maternal practice on child feeding $(\mathrm{p}<0.05)$ (Table 8$)$. Children whose mothers age had greater than or equal to 30 years were $86 \%$ less likely to be have poor practice on child feeding than children whose mothers age had in between $15-19$ years $(\mathrm{AOR}=0.14,95 \% \mathrm{CI}, 0.03-0.63)$. Use of treated water showed statistically significant association with poor practice on child feeding. Children whose households use treated water had 12.47 times more likely to have poor practice on child than those whose households did not treat water $(\mathrm{AOR}=12.47,95 \% \mathrm{CI}, 5.82$ 26.7). Children whose households had spent greater than equal to 60minutes to fetch water had 1.78 times more likely to have poor practice on child than those whose households had spent less than equal to 60 minutes to fetch water $(\mathrm{AOR}=1.78,95 \% \mathrm{CI}, 1.00-3.16)$.

Table 8 Predictors of maternal practices on child feeding among children aged 6-23months in pastoralist communities, BennaTsemayWoreda, South Omo Zone, Southern Ethiopia, 2016

\begin{tabular}{|c|c|c|c|c|c|}
\hline Variable & $\begin{array}{l}\text { Poor practices } \\
\text { n (\%) }\end{array}$ & $\begin{array}{l}\text { Good } \\
\text { practices n (\%) }\end{array}$ & Crude OR $(95 \% \mathrm{CI})$ & Adjusted OR (95\%CI) & P-value \\
\hline \multicolumn{6}{|l|}{ Mother's age (in years) } \\
\hline $15-19$ years & $12(54.5)$ & $8(36.4)$ & 1 & I & 0.04 \\
\hline 20-24 years & $95(46.1)$ & $91(44.2)$ & $\mathrm{I} .43(0.56,3.67)$ & $0.22(0.05,0.93)$ & 0.058 \\
\hline $25-29$ years & $130(49.2)$ & $115(43.6)$ & I.32(0.52, 3.36) & $0.25(0.06,1.04)$ & $0.011 * *$ \\
\hline$\geq 30$ years & $113(73.9)$ & $20(13.1)$ & $0.26(0.09,0.73)$ & $0.14(0.03,0.63)$ & \\
\hline \multicolumn{6}{|l|}{ Use of treated water } \\
\hline No & $254(74.1)$ & $60(17.5)$ & 1 & I & \\
\hline Yes & $96(31.8)$ & 174(57.6) & $7.67(5.26,11.17)$ & $12.47(5.82,26.7)$ & $0.001 * *$ \\
\hline \multicolumn{6}{|c|}{ Time to fetch water in minutes } \\
\hline$<60$ minutes & $238(65.2)$ & $88(24.1)$ & I & I & \\
\hline$\geq 60$ minutes & $112(40.0)$ & $146(52.1)$ & $3.52(2.49,4.98)$ & $1.78(1.00,3.16)$ & $0.047^{* *}$ \\
\hline \multicolumn{6}{|c|}{$\begin{array}{l}\text { Major source of information on } \\
\text { child feeding }\end{array}$} \\
\hline \multicolumn{6}{|c|}{ Radio } \\
\hline Magazines and news paper & $\mathrm{I}(\mathrm{I} 2.5)$ & $3(37.5)$ & I & I & 0.096 \\
\hline Health extension workers & $4(66.7)$ & $2(33.3)$ & $0.16(0.01,2.82)$ & $0.04(0.001,1.75)$ & 0.011 \\
\hline \multirow[t]{2}{*}{ Relative/friend/family } & $203(45.4)$ & $207(46.3)$ & $0.34(0.03,3.29)$ & $0.03(0.002,0.46)$ & $0.003^{* *}$ \\
\hline & $70(81.4)$ & $\mathrm{II}(12.8)$ & $0.05(0.005,0.55)$ & $0.0 \mathrm{I}(0.00 \mathrm{I}, 0.23)$ & \\
\hline \multicolumn{6}{|l|}{ Maternal occupation } \\
\hline Housewives & $163(40.8)$ & $210(52.5)$ & $\mathrm{I}$ & I & 0.755 \\
\hline Livestock herding & $35(72.9)$ & $8(16.7)$ & $0.17(0.08,0.39)$ & $0.83(0.28,2.5 \mathrm{I})$ & $0.001 * *$ \\
\hline Farming & I46(78.9) & $13(7.0)$ & $0.06(0.03,0.12)$ & $0.16(0.06,0.45)$ & \\
\hline \multicolumn{6}{|l|}{ Availability of health service } \\
\hline Yes & $135(73.4)$ & $20(10.9)$ & 1 & I & \\
\hline No & $215(46.6)$ & $214(46.4)$ & $6.7 I(4.04,11.14)$ & $5.8 I(2.04,16.5)$ & $0.001 * *$ \\
\hline \multicolumn{6}{|l|}{ Minimum dietary diversity } \\
\hline$<4$ food groups/day & $278(65.6)$ & $106(25.0)$ & $\mathrm{I}$ & I & \\
\hline$\geq 4$ food groups/day & $72(32.6)$ & $128(57.9)$ & $4.66(3.23,6.7 I)$ & $2.37(1.20,4.67)$ & $0.012 * *$ \\
\hline
\end{tabular}




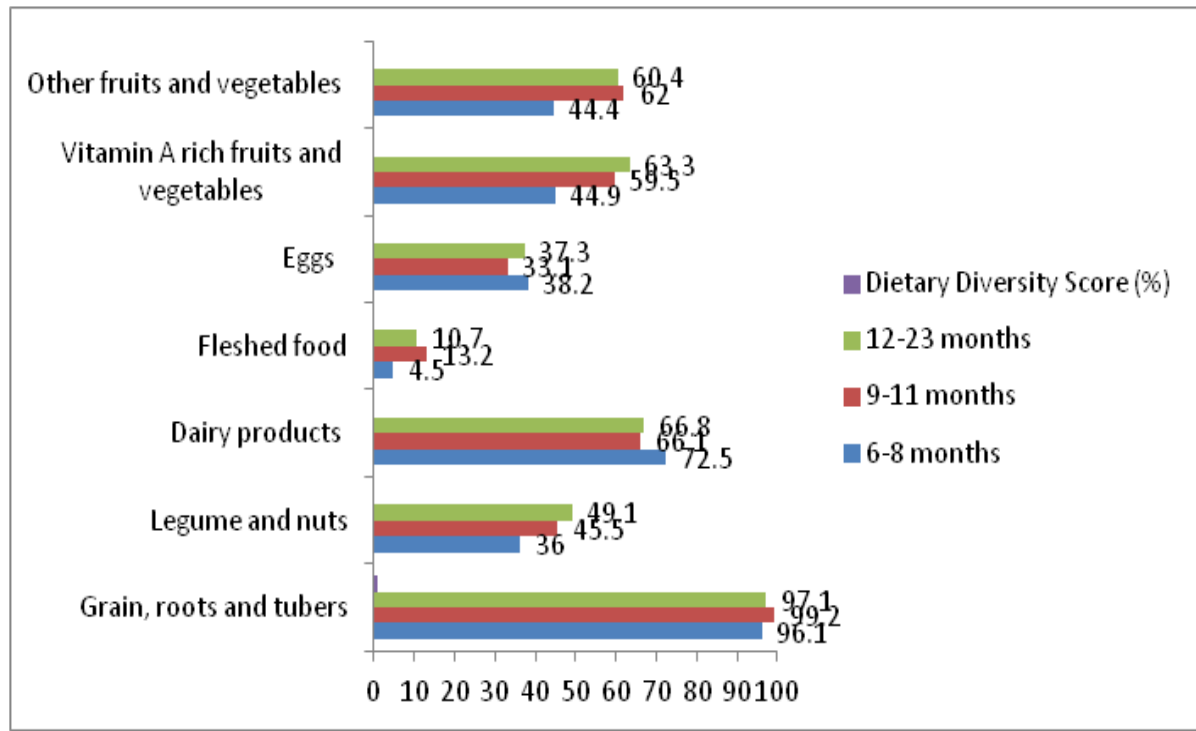

Figure I Food Frequency consumption (FFQ) of pastoralist children aged 6-23 months in BennaTsemayworeda, South Omo Zone, Southern Ethiopia, $2016(n=645)$

Children whose mothers major source of information on child feeding from relative/friend/family were $99 \%$ less likely to be have poor practice on child feeding than children whose mothers major source of information on child feeding from radio (AOR $=0.01,95 \%$ CI, 0.001-0.23). Maternal occupation was statistically significant association with poor practice of child feeding. Children whose mothers are farmers in their occupation were $84 \%$ less likely to have poor practice on child compared to those children's whose mothers were housewife in their occupation ( $\mathrm{AOR}=0.16,95 \% \mathrm{CI}, 0.06$ $0.45)$. Children whose mothers hadn't access to health service were 5.81 more likely to have poor practice on child compared to those children whose mothers had access to health service (AOR=5.81, 95\% CI, 2.04-16.5). Children whose mothers gave greater than or equal to 4 food groups/day were 2.37 more likely to have poor practice on child compared to those children whose mothers gave less than 4 food groups/day (AOR=2.37, 95\% CI, 1.20-4.67). Maternal education, father's education, occupation of household head, wealth index, child ever vaccinated, child ever taken to health institution and hand washing before and after feeding child didn't show significant association with mothers practice towards child feeding $(p<0.05)$ and adjusted for those significant variables.

\section{Discussion}

The present study revealed that $350(54.3 \%)$ of the respondents had adequate and $295(45.7 \%)$ had inadequate knowledge about appropriate child feeding practices. Out of the total, $234(36.3 \%)$ and $350(54.3 \%)$ mothers had good and poor child feeding practices, respectively. This might be due to the influences of cultural and traditional malpractices influencing current breast feeding status, colostrums feeding practice, exclusive breastfeeding, breastfeeding frequency, age at complementary food started and lack of knowledge about the importance of appropriate breastfeeding. It was found that, $65.6 \%$ of the study participated children consumed less than 4 food groups in the last 24-hrs preceding the survey with mean dietary diversity score (DDS) being $3.7 \pm 1.48$. However, only $11.5 \%$ of the children consumed less than 3meals/day with mean meal frequency of $1.88 \pm 0.31$. Similar results were reported by ${ }^{8}$ from Lahore and from India. According to this study, households having two and above number of under five children had $54 \%$ less likely to be have inadequate knowledge on child feeding than households having one under five children. This could be partially explained in that, as the family members increase, there will be sharing of resources in household including food which will result in lack of adequate food especially for children. ${ }^{10}$ Families with more children generally devote less time to take care of their children. ${ }^{11}$

Based on the findings of this study, households whose fathers having primary education 5.24times more likely to have inadequate knowledge on child feeding as compared to those households whose fathers have no formal education. In contrary father's education did not have any correlation with infant feeding practices. ${ }^{10}$ Children whose households with the richest wealth quintile were 23.01times more likely to be having inadequate knowledge on child feeding than children whose households had lowest wealth quintiles. This might be due to children from greater income/rich families can have improved nutritional status. Rich families can afford more nutritious food, clean water, hygiene, and health care. This allows them to have a more diversified diet and to attain more effective childcare activities. At the community level, greater income means better access to quality health care, improved water, and sanitation systems and greater access to information. The finding of this study showed that maternal occupation was statistically significant association with inadequate knowledge and poor practice of child feeding. Children whose mothers are farmers in their occupation were $92 \%$ less likely to have inadequate knowledge and $84 \%$ less likely to have poor practice on child compared to those children's whose mothers were housewife in their occupation. This study was consistent with a study conducted in Philippines which showed housewives would normally stop nursing their infants within 2years and have unlimited time available to feed their infants. ${ }^{12}$ Another study in Malaysia also reported that factors found to influence infant feeding practices are maternal occupation. ${ }^{13}$

Present finding revealed that, use of treated water showed statistically significant association with poor practice on child feeding. Children whose households use treated water had 12.47times more 
likely to have poor practice on child than those whose households did not treat water. Children whose households had spent greater than equal to 60 minutes to fetch water had 1.78 times more likely to have poor practice on child than those whose households had spent less than equal to 60 minutes to fetch water. Children whose mothers major source of information on child feeding from relative/friend/family were $99 \%$ less likely to be have poor practice on child feeding than children whose mothers major source of information on child feeding from radio. The following recommendations are suggested based on the results of this study: Provide sustained nutrition education programs to mothers focusing on appropriate feeding practice through community-based nutrition programs is critical to accelerate improvement in children nutritional status in the study area. Nutrition programs should also pay attention to cultural beliefs and food taboos on infant and young child feeding. Use of family planning should be encouraged to help the family to have small family size which can improve household income and proper sharing of resources.

There is a need to address the issues of polygamous marriage through multidisciplinary approach at community level should be carried out to consequently reduce wasting among children. Close monitoring of the gap between poorest, middle, and richest households can help in the reduction of the gap in nutritional status between children in the highest and lowest socioeconomic quintiles. The findings of this study had its implications for health care workers and other concerned bodies including policy makers to carry out the national nutrition strategy on IYCF by considering the living conditions of the pastoralist communities. Further longitudal studies should be done to see unexplored variables (Antenatal care, seasonal factors, household food security and dietary adequacy of pastoralist children in the community) that were not included in this study. Media should be involved in promotion of child feeding practices. Issues on child nutrition especially in feeding practices should be given high priority in national plan. Program managers, policy makers and local administrators should pay attention to improve the mother's knowledge towards child feeding practices, cultural food taboos, and dietary diversity for better child nutritional status.

\section{Strengths of the study}

Among the notable strengths of this study, it is the first study done in this themtic group of Benna and Tsemay children which gives important base line information regarding the mother's knowledge, practice and attitude towards child feeding in pastoralist communities to all concerned partners. The study included large sample size in order to enhance the power of the findings. Incorporation of both quantitative and qualitative study designs could be considered as the strength. The study used dietary assessment to assess the food consumption pattern of pastoralist children in the study area. In this study also used wealth index to assess socioeconomic status of household since underestimation and overestimation of monthly income. In addition, logistic regression was also used in the statistical analysis, so the interaction was analyzed and confounding factors were controlled, also the most important factors were identified.

\section{Limitations of the study}

The cross sectional study design may not enable to determine causal relationships. There may be recall bias in 24 hour recall dietary assessment.

\section{Conclusion}

Overall of mothers had poor IYCF practices. Majority of mothers had a positive attitude about breastfeeding initiation, provision of colostrums for newborn infants and exclusive breast feeding in the first six months among children aged 6-23months old in the community. But certain mothers had negative attitude about introduction of complementary feeding and food frequency consumption. The predictors of inadequate maternal knowledge towards child feeding were having large number of under five children (2-4 child), polygamous marriage, fathers having primary education, being from pastoralist, richest wealth quantile household, use of treated water, time to fetch water, birth interval between the recent two birth and farming as maternal occupation. Older age mothers ( $\geq 30$ years), use of treated water, time to fetch water, major source of information on child feeding, farming as maternal occupation, availability of health service and minimum dietary diversity are the independent predictors of maternal practices on child feeding.

\section{Acknowledgement}

None.

\section{Conflict of interest}

The authors declare that there is no conflict of interest.

\section{References}

1. Black RE, Victora CG, Walker SP, et al. Maternal and child under nutrition and overweight in low-income and middle income countries. Lancet. 2013;382:427-451.

2. Saha K, Frongillo E, Alam D, et al. Appropriate infant feeding practices result in better growth of infants and young children in rural Bangladesh. Am J Clin Nutr. 2008;87(6):1852-1859.

3. WHO. Infant and young child feeding. Model chapters for medical professional and allied health professionals. Geneva. 2010

4. Emily M. Relationship between breastfeeding practices and nutritional status of children aged 0-24 months in Nairobi, Kenya. African Journal of Food Agriculture Nutrition and Development. 2010;10:4.

5. Comprehensive Food Security and Vulnerability Analysis (CFSVA). Ethiopia 2014.

6. Central Statistical Agency (CSA) [Ethiopia]. The 2007 population and Housing Census of Ethiopia. Statistical Summary Report at National Level, Addis Ababa, Ethiopia.

7. WHO, UICEF, UC Davis, et al. Indicators for assessing infant and young child feeding practices, part 1 definition: conclusions of a consensus meeting held 6-8 November in Washington D.C., USA. 2007.

8. Chuodhry Humayun. Weaning practices and their determinants among mothers of infants. Biomedica. 2007;23:120-124.

9. Aggarwal A, Verma S, Faridi M. Complimentary feeding-reasons for inappropriateness in timing, quantity and consistency. Indian J Paediatr. 2008;75(1):49-53.

10. Teklebrhan T. Predictors of Nutritional Status of Children Visiting Health Facilities in Jimma Zone, South West Ethiopia. International Journal of Advanced Nursing Science and Practice. 2012;(1):1-11.

11. Fentaw R, Bogale A, Abebaw D. Prevalence of child malnutrition in agro-pastoral households in Afar Regional State of Ethiopia. Nutr Res Pract. 2013;7(2):122-131.

12. Shazia Memon, Salma Shaikh, Tasneem Kousar, et al. Assessment of infant feeding practices at a tertiary care hospital. J Pak Med Assoc. $2010 ; 60(12)$

13. Abada TS, Trovato F, Lalu N. Determinants of breastfeeding in the Philippines: a survival analysis. Soc Sci Med. 2001;52(1):71-81. 